\title{
Сафаева C.P. \\ Основные аспекты совершенствования сферы туризма в период мировой пандемии
}

Ташкентский государственный экономический университет (Узбекистан, Ташкент)

doi: 10.18411/trnio-11-2021-112

\section{Аннотация}

В данной научной статье анализируется ситуация, наблюдаемая в мировой туристической индустрии и объемы туристических услуг стран в период пандемии COVID19 в 2019-2021 годах. Цель научной статьи - изучить основные спады и динамику туризма в странах, активно вовлеченных в мировую экономику и в туристические услуги, разработать предложения по развитию отрасли в постпандемический период. На основе анализа разработаны предложения по развитию туристической индустрии в кризисных ситуациях.

Ключевые слова: пандемия, туризм, правительство, финансовые меры, занятость, ЮНВТО, индустрия туризма, кризис, международный туризм, международные и внутренние туристы.

\section{Abstract}

This scientific article analyzes the situation observed in the global tourism industry and the volume of tourism services of countries during the COVID-19 pandemic in 2019-2021. The purpose of the scientific article is to study the main recessions and dynamics of tourism in countries actively involved in the world economy and tourism services, to develop proposals for the development of the industry in the post-pandemic period. Based on the analysis, proposals have been developed for the development of the tourism industry in crisis situations.

Keywords: pandemic, tourism, government, financial measures, employment, UNWTO, tourism industry, crisis, international tourism, international and domestic tourists.

\section{Введение}

Современный мир вступает в эпоху услуг - к такому выводу все чаще приходят специалисты, занимающиеся прогнозами развития мировой экономики и международных экономических отношений. Одним из важнейших сегментов сферы услуг является международный туризм. К примеру, количество международных визитов с 1950 года увеличилось с 25 миллионов в 2019 году примерно до 1,5 миллиарда. По данным Всемирной туристской организации ООН (ЮНВТО), к 2030 году общее количество иностранных и внутренних туристов превысит 17 миллиардов [1].

Число международных туристических прибытий в 2020 году сократилось на один миллиард или 74\% из-за пандемии коронавируса и связанных с ней повсеместных ограничений на поездки.

Экспортные доходы от туризма сократились на \$1,3 трлн, что в 11 раз превышает потери от глобального экономического кризиса 2009 года.

Поскольку туризм - это сфера, непосредственно связанная с пересечением государственных границ и взаимодействием других сфер, пандемия оказала влияние на отрасль. Кризис, вызванный пандемией, нанес большой ущерб малому и среднему бизнесу, работающему в сфере туризма. Это в восемь раз больше, чем ущерб, нанесенный мировым финансово-экономическим кризисом 2008-2009 годов. Десятки авиакомпаний и туроператоров по всему миру также покинули рынок из-за экономического спада, роста цен на топливо и снижения спроса на билеты и пакетные туры. 
В этот период во избежание больших убытков в одних странах при поддержке государств оказывалась экономическая и финансовая поддержка туристического бизнеса, в других удалось сохранить тенденции развития за счет использование онлайн-туризма, в странах с низкой заболеваемостью поощрялся внутренний туризм.

Поскольку спад в сфере туризма влияет на статистику сектора услуг, он также отражается на стоимости валового внутреннего продукта, занятости, экспорта и импорта. По этой причине государственная поддержка туристического бизнеса в период пандемического кризиса предотвратит серьезные потери в макроэкономике. Исходя из вышесказанного, тема данной научной статьи является актуальной.

Целью научной статьи является изучение изменений туризма в мировой экономике вызванный в результате пандемии, разработка предложений по развитию отрасли в постпандемический период.

\section{Степень изученности темы}

Кризисные исследования, влияющие на туристическую отрасль, не имеют различных подходов и привели к отсутствию знаний об интенсивности воздействия проблем на туристическую отрасль из-за туристических кризисов и методов борьбы с ними [3, 4]. Антикризисное управление в туризме в основном рассматривается в национальном или региональном контексте, где триггерный элемент имеет различную природу, например, стихийные бедствия, эпидемии или социальные заболевания [5]. Если в прошлом антикризисные меры были неактивными, то в последние годы исследования расширились, предлагая активный ответ, основанный на доверии к коммуникации, информации и кризисному менеджменту.

Последствия пандемии, вызванные высококонтагиозными вирусами, стали предметом многочисленных исследований. 2019 году Хунг К. и др. [7] изучили влияние SARS и H1N1 2003 года на индустрию туризма в Гонконге. В результате проведенных исследований были разработаны меры и дорожная карта для развития туризма в Гонконге.

Южно-корейский ученый Ким П. и другие подчеркнули важность планов действий в чрезвычайных ситуациях для эффективного управления кризисом атипичной пневмонии в Южной Корее в 2003 году [8], призвав к созданию системы управления кризисами и обучению лиц, принимающих решения, и широкой общественности, как бороться с санитарным кризисом. Южная Корея была одной из стран, которые лучше всего справились с ситуацией, вызванной COVID-19, учитывая ее предыдущий опыт и извлеченные уроки.

Среди узбекских ученых Алимова М. Т. [9] изучила актуальность развития туризма в посткризисный период. Согласно её исследованиям, были предложены следющие: внедрение электронных музейных и выставочных гидов устанавливаемых на мобильные телефоны; подготовка мультимедийных презентаций, отражающих туристический потенциал региона; организация виртуальных туров путем размещения на интернет-портале «Самарканд - Туристический центр»; строительство средневековой гостиницы и использование «анимационных» программ; предложения по формированию интерактивной туристической информационной системы за счет совершенствования геоинформационных систем.

\section{Анализ и результаты}

По данным ЮНВТО, в 2020 году сокращение мировых туристических потоков составило 74 процента. В Азиатско-Тихоокеанском регионе, где во время пандемии применялось больше всего запретов, снижение составило 84 процента. Следует отметить, что ни в одном регионе мировой экономики не наблюдалось роста туризма (рис.1). 


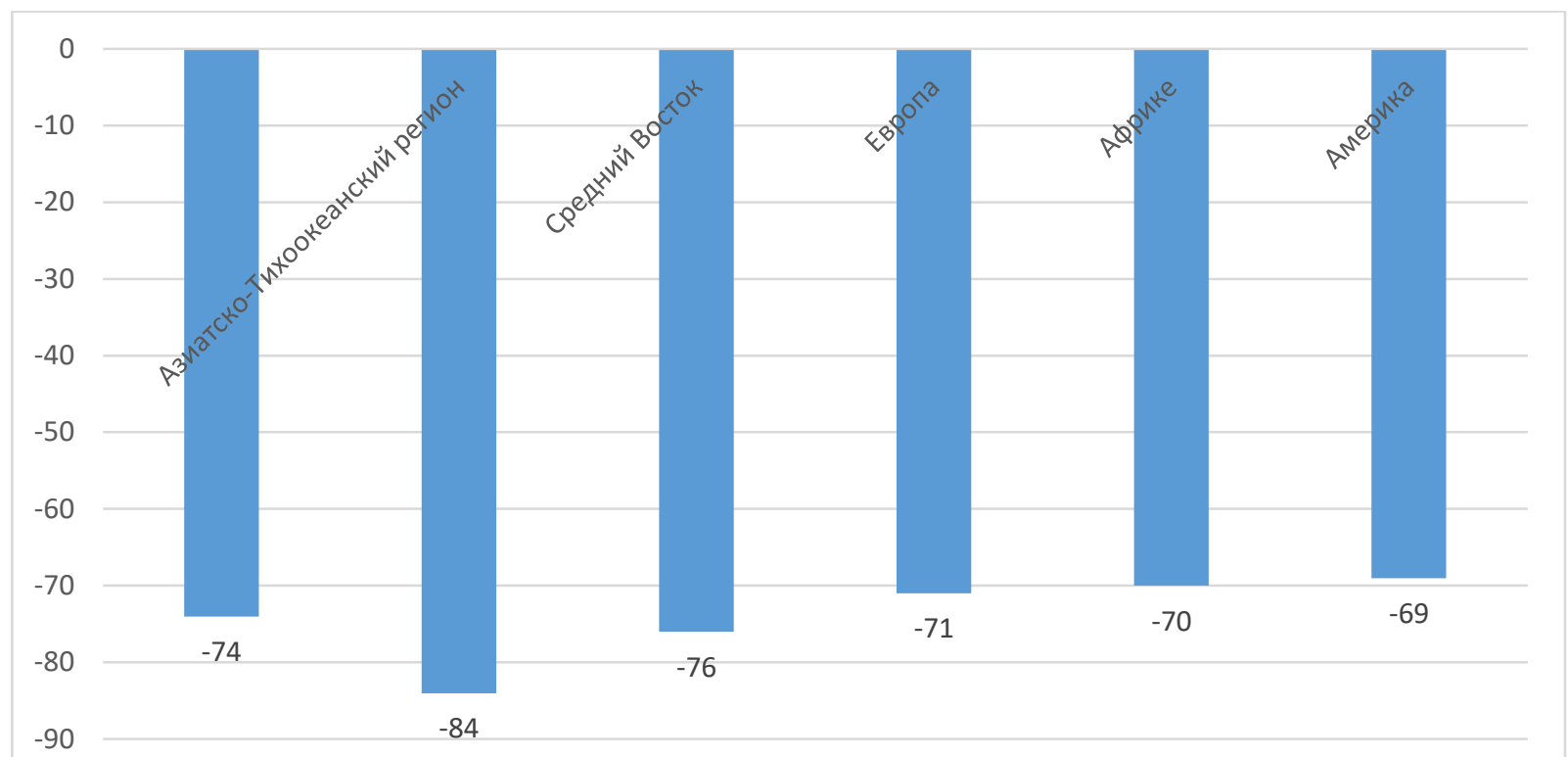

Рисунок 1. Показатели сокращения международных туристических потоков в 2020 году, в проиентах [10]

Сложная эпидемиологическая ситуация во множества государствах мира в начале 2021 года отразилась на туристической активности. Введение обязательного тестирования, карантин и в некоторых случаях полное закрытие границ препятствовали возобновлению международных поездок в начале 2021 года. Кроме того, скорость и распространение вакцинации были ниже, чем предполагалось, собственно что ещё более задержало возобновление туризма.

Наибольшее снижение доходов от туризма в странах произошло в Испании, Таиланде, Японии, России и Великобритании. В этих странах снижение составило 80 процентов и более. Это можно объяснить применением строгих карантинных мер в этих странах. В Италии, Германии, Франции и Австралии снижение составило менее 50 процентов. Однако в результате применения государственных требований к внутреннему туризму в США, Германии, Франции и России в этих странах наблюдаются темпы роста. Развивающиеся страны больше всего пострадали от туристической пандемии. На эти страны приходилось наибольшее снижение количества туристов в 2020 году на 60-80 процентов. В результате спада туризма в странах Южной Америки произошло снижение ВВП до 11 процентов.

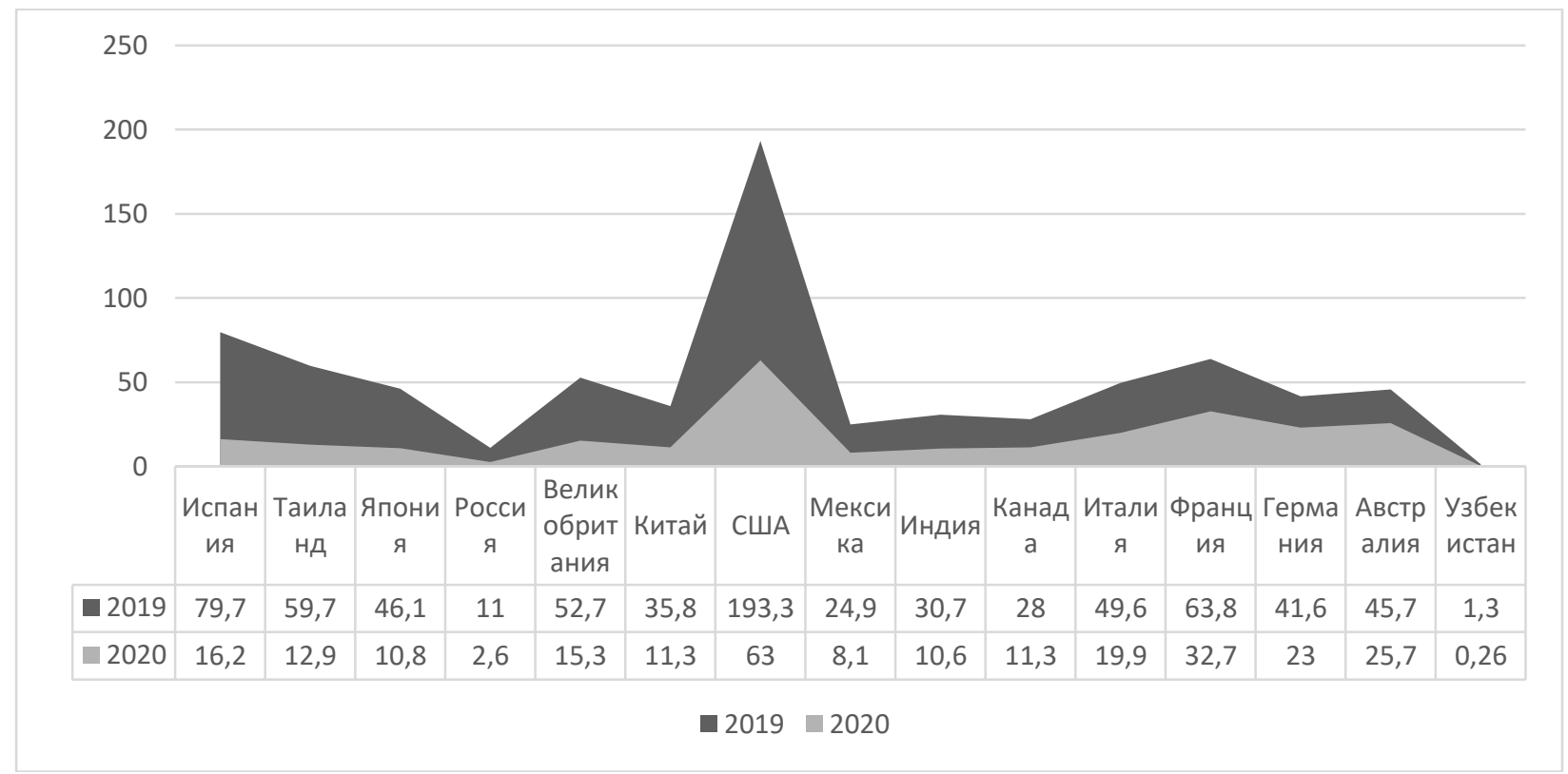

Рисунок 2. Выручка от туризма в 2019-2020 годах, млрд долларов 
Количество туристов, отправившихся в этот период в другие страны, уменьшилось на 85\% по сравнению с показателем аналогичного периода 2019 года - до начала пандемии коронавируса. Кроме того, количество международных путешественников за 5 месяцев 2021 года было на 65\% меньше, чем за соответствующий период 2020 года.

По прогнозам ЮНВТО, туризм может частично восстановиться во второй половине 2021 года. Основной причиной этого стало постепенное открытие туристических границ стран, ослабление карантинных требований и призывы к массовой вакцинации. В частности, в июне 2021 года количество стран, полностью закрывших границы для туризма, упало до 63 из 69 стран в феврале. Большинство закрытых помещений находится в АзиатскоТихоокеанском регионе (33) и Европе (7).

Количество иностранных туристов, посетивших Узбекистан в 2020 году, составило 1,5 миллиона (в 2019 году этот показатель составлял 6,7 миллиона, в 2018 году - 5,3 миллиона), количество внутренних туристов - 1,8 миллиона. Иностранным туристам было оказано услуг на сумму 261 миллион долларов. Следует отметить, что хотя количество иностранных туристов, посетивших страну за первые шесть месяцев 2021 года, не показало роста по сравнению с аналогичным периодом 2020 года, ослабление карантинных мер в стране позволило развитию внутреннего туризма и в результате количество местных туристов достигло 7,5 миллионов. Именно в период пандемии новые виды туризма в стране создали возможности для развития МICЕ-туризма, кинотуризма.

Наиболее важной проблемой государственного масштаба остаются проблемы в области перевозок. Уровень цен национального перевозчика, который является ориентиром и для других перевозчиков совершенно высок и затраты только на перевозку доходят до 50\% всех затрат по организации туров. Отсутствие гибкости национального авиаперевозчика в разработке и поддержке чартерных специальных рейсов по разным странам и городам, откуда ожидается определенный поток туристов разных категорий. Также отсутствие инициативы национального перевозчика в договоренностях с другими перевозчиками о планировании дополнительных полетов по популярным направлениям и в сезонные месяцы по приемлемым ценам.

В железнодорожных перевозках нужно отметить отсутствие стабильной электронной торговли билетами внутри страны и невозможность планирования внутренних перевозок пассажирскими поездами за много месяцев вперед [13].

Вышеназванные проблемы не являются исчерпывающими. Однако они охватывают довольно широкий перечень барьеров на пути развития туризма в Узбекистане.

В статистике туризма возврат к уровню международных посещений в 2019 год может занять от 2,5 до 4 лет [14]. Для этого государствам необходимо принять меры по поддержке финансовой, экономической, эпидемиологической и банковской сферы.

Таблииа 1

Основные меры по обеспечению устойчивости туристического сектора

\begin{tabular}{|c|c|c|c|}
\hline & $\begin{array}{c}\text { На международном } \\
\text { уровне }\end{array}$ & На национальном уровне & $\begin{array}{c}\text { На промышиленном } \\
\text { уровне }\end{array}$ \\
\hline Финансовые меры & $\begin{array}{c}\text { финансовая помощьь } \\
\text { странам со } \\
\text { значительньм } \\
\text { туристическим } \\
\text { сектором для } \\
\text { финансирования } \\
\text { планов по } \\
\text { предотвращению } \\
\text { массовых увольнений } \\
\text { из-за пандемии } \\
\text { СОУІD-19 }\end{array}$ & $\begin{array}{c}\text { путем выдачи банковских } \\
\text { кредитов под финансовые } \\
\text { гарантии; отсрочка } \\
\text { погашения долгов, налогов } \\
\text { на бизнес и самозанятость } \\
\text { на определенный период } \\
\text { времени; краткосрочная } \\
\text { поддержка ликвидности; } \\
\text { возможности } \\
\text { кредитования } \\
\text { туроператоров. }\end{array}$ & $\begin{array}{c}\text { финансовая помощьь, } \\
\text { предоставляемая } \\
\text { наиболее пострадавщим } \\
\text { отраслям }\end{array}$ \\
\hline
\end{tabular}




\begin{tabular}{|c|c|c|c|}
\hline Экономические меры & $\begin{array}{c}\text { обеспечение } \\
\text { экономического } \\
\text { роста с сохранением } \\
\text { покупательской } \\
\text { способности }\end{array}$ & $\begin{array}{c}\text { предоставление ицифрового } \\
\text { оборудования и услуг; } \\
\text { выдача государственных } \\
\text { гарантий; }\end{array}$ & $\begin{array}{c}\text { изменить правила } \\
\text { банкротство; } \\
\text { переговорь с банковской } \\
\text { системой о } \\
\text { реструктуризации } \\
\text { кредитной системь. }\end{array}$ \\
\hline Санитарные меры & $\begin{array}{c}\text { поочрение туризма } \\
\text { путем продвижения } \\
\text { потенциальньхх } \\
\text { туристов. }\end{array}$ & $\begin{array}{c}\text { инициативы по воспитанию } \\
\text { чувства безопасности для } \\
\text { здоровья у местных и } \\
\text { иностранных туристов: } \\
\text { тестирование } \\
\text { туристического персонала, } \\
\text { ограничение } \\
\text { возможностей, } \\
\text { обеспечение удаленности, } \\
\text { регулярная дезинфекция } \\
\text { всех поверхностей, } \\
\text { мониторинг. }\end{array}$ & $\begin{array}{c}\text { адаптация услуг к } \\
\text { потребностям } \\
\text { клиентов }\end{array}$ \\
\hline $\begin{array}{c}\text { Поддержка занятости } \\
\text { населения }\end{array}$ & & $\begin{array}{c}\text { мониторинг, разработка } \\
\text { методических указаний, } \\
\text { правил, рекомендаций. }\end{array}$ & $\begin{array}{c}\text { Страх перед пандемией } \\
\text { СОУІD-19 и выбор } \\
\text { путешествий; } \\
\text { предоставление } \\
\text { инновационного опьта } \\
\text { за счет использования } \\
\text { цифровых медиа и } \\
\text { дополненной } \\
\text { реальности. }\end{array}$ \\
\hline
\end{tabular}

Спад в сфере туризма также отразился на уровне безработицы. В частности, в среднем 5,5 процента безработицы были связаны с туризмом. Наибольшие убытки терпят те, кто частично занимается туризмом, и те, кто работает сезонно.

Роль экономических и финансовых мер имеет решающее значение в борьбе с пандемией COVID-19, особенно в сфере туризма, при этом необходимо учитывать следующие цели [15]:

- обеспечение функциональных возможностей туроператоров за счет регулярного тестирования кадров индустрии гостиприимства и определения приоритетности вакцинации;

- предоставление туроператорам финансовой помощи, финансовых и экономических возможностей для выживания на рынке;

- обеспечивать адекватные финансовые ресурсы для работников туристического бизнеса, пострадавших от кризиса (расширенные пособия по безработице);

- поддержка частных компаний посредством субсидий, кредитных возможностей, государственных гарантий;

- поддерживать внутренний туризм, поощряя граждан планировать отдых в стране.

\section{Выводы и предложения}

Исследования показали, что, хотя туризм - это сфера, которая может работать и процветать как бизнес, во время кризиса нуждается в государственной поддержке. Если малому и среднему бизнесу нужна финансовая поддержка, возможность платить проценты по кредитам и отложенные налоги, то крупному бизнесу нужны налоговые каникулы, социальная поддержка своих сотрудников.

Исходя из вышеизложенного, автор предлагает следующее.

- Дальнейшее развитие индустрии туризма напрямую зависит от экономических и санитарных мер страны и в период кризиса государство обязано разработать специальные дорожные карты для развития туризма. 
Эти дорожные карты должны включать экономическую и финансовую поддержку туристического бизнеса в постпандемический период. Дорожные карты должны включать субсидии представителям туристического бизнеса, ссуды под низкие проценты и отпуск по кредитам.

- Для восстановления сферы туризма в постпандемический период необходимо придерживаться строго определенных санитарных правил (носить маску, выдерживание дистанции, вакцинация) для представителей туристической индустрии (аэропортов, отелей, музеев и ресторанов).

- Как и все предыдущие кризисы, нынешний проявит и усилит уже давно появившиеся тенденции. Среди них - цифровизация и уберизация. Наряду с развитием новых форм туризма во время пандемии важное значение имеет развитие онлайн-туризма. Для этого требуется разработка специальных программ и сайтов. Развитие онлайн-туризма позволяет взглянуть на туристический потенциал страны под новым углом.

- Учитывая, что большинство представителей туристической отрасли - это малый и средний бизнес, необходимо предоставить кредитные льготы и субсидии, возможность разработки новых турпакетов в внутреннем туризме.

- Необходимо поострить инфраструктуру оздоровительных, медицинских госпиталей, имеющих международную сертификацию или хотя бы врачей различных базовых специальностей с международными сертификатами. В Ташкенте и Самарканде имеются такие госпитали. Но и здесь, информация об их услугах и квалификации персонала не общедоступна и неизвестна широкому кругу туроператоров.

- Необходимо частными усилиями создать веб-сайт, на котором можно продавать стандартные страховые пакеты медицинских услуг, организаций, имеющих международные сертификаты, врачей с международными сертификатами.

- Есть необходимость в создании услуг по сопровождению больших групп туристов с определенным возрастными и иными рисками местным медицинским персоналом, владеющим базовыми иностранными языками и имеющими международные сертификаты.

- Нужно ускорить включение отечественных гостиниц и других средств размещения в международные системы букинга (booking.com, hotels.com, tripadvisor.com и другие). Большинство малых гостиниц частного сектора не могут конкурировать по ценам и условиям размещения с теми гостиницами, которые приняли все условия вышеназванных электронных операторов системы букинга, и они нуждаются в определенной системе субсидирования убытков хотя в первые 3 критических года. Данное обстоятельство является смежной ответственностью государства и частного сектора. Возможным решением такого положения могла бы быть система краткосрочного субсидирования малых гостиниц (действующих) под конкретные индивидуальные программы интеграции в мировую туристическую индустрию с последующим возвратом государству субсидированных средств в течение долгосрочного периода.

$$
* * *
$$

1. https://www3.wipo.int/wipogreen/en/news/2020/news_0034.html

2. https://www.atorus.ru/news/press-centre/new/54073.html

3. Pforr, C. Tourism in Post-Crisis is Tourism in Pre-Crisis: A Review of the Literature on Crisis Management in Tourism. 2006. Available online: https://espace.curtin.edu.au/handle/20.500.11937/36215 (accessed on 1 May 2021).

4. Ghaderi, Z.; Henderson, J.C. Japanese tsunami debris and the threat to sustainable tourism in the Hawaiian Islands. Tour. Manag. Perspect. 2008, 8, 98-105. 
5. Avraham, E. Destination image repair during crisis: Attracting tourism during the Arab Spring uprisings. Tour. Manag. 2015, 47, 224-232.

6. Butler, R.W. Sustainable tourism: A state-of-the-art review. Tour. Geogr. 1999, 1, 7-25.

7. Hung, K.K.C.; Carman, K.M.M.; Yeung, M.P.S.; Chan, E.Y.Y.; Graham, C.A. The role of the hotel industry in the response to emerging epidemics: A case study of SARS in 2003 and H1N1 swine flu in 2009 in Hong Kong. Glob. Health 2018, 14, 117.

8. Третья всемирная конференция по снижению риска бедствий. 14-18 марта 2015 года / Сендай - Япония. https://www.unisdr.org/files/45069_proceedingsthirdunwcdrrru.pdf

9. Алимова М. Т. Особенности и тенденции развития регионального туристического рынка (на примере Самаркандской области). Автореферат докторской диссертации. Самарканд - 2017. файл: I// C: /Users/User/Downloads/home_tourism_market_development_characteristics_and_trends_example_of_samarkand_r egion.pdf

10. Подготовлено автором на основе данных ЮНВТО.

11. https://www.atorus.ru/news/press-centre/new/56167.html

12. https://www.gazeta.uz/ru/2021/01/09/turism-stat/

13. Safaeva, S. (2020). Investment in the tourism sector: the pandemic and its impact. Архив научных исследований, (32).

14. https://www.interfax.ru/world/741811

15. Campiranon, K.; Scott, N. Critical success factors for crisis recovery management: A case study of Phuket hotels. J. Travel Tour. Mark. 2014, 31, 313-326.

Тменова Е.С., Калюгина И.В.

Совершенствование управления дебиторской и кредиторской задолженностью предприятия

ФГБОУ ВО Воронежский государственный аграрный университет имени императора Петра I

(Россия, Воронеж)

doi: 10.18411/trnio-11-2021-113

\section{Аннотация}

Данная статья посвящена проблемам, связанным с управлением кредиторской и дебиторской задолженности. Несомненно, устойчивость финансового состояния организации в условиях современной рыночной экономики зависит во многом от эффективности управления кредиторской и дебиторской задолженностью. Актуальность данной темы определяется теоретической и практической значимостью проблемы. В целях повышения финансовой устойчивости и платежеспособности предприятия авторы предлагают список рекомендаций по управлению расчетами с контрагентами.

Ключевые слова: дебиторская задолженность, кредиторская задолженность, управление, контроль.

\section{Abstract}

This article is devoted to the problems associated with the management of accounts payable and receivables. Undoubtedly, the stability of the financial condition of an organization in the conditions of a modern market economy largely depends on the effectiveness of the management of accounts payable and receivables. The relevance of this topic is determined by the theoretical and practical significance of the problem. In order to increase the financial stability and solvency of the enterprise, the authors offer a list of recommendations for managing settlements with counterparties.

Keywords: accounts receivable, accounts payable, management, control.

В системе отношений между предприятием и его контрагентами возникновение задолженностей является объективным процессом. По мере расширения масштабов производства и усложнения хозяйственных связей в процессе финансово-хозяйственной 